\title{
Pulmonary hypertension in late-onset Methylmalonic Aciduria and Homocystinemia: a case report
}

\author{
Ling-yi Wen ${ }^{1}$, Ying-kun Guo ${ }^{1}$ and Xiao-qing Shi $^{2^{*}}$ (D)
}

\begin{abstract}
Background: Methylmalonic Aciduria and Homocystinemia, cobalamin C (cblC) is an inherited disease of vitamin $\mathrm{B}_{12}$ metabolism with a wide spectrum of clinical manifestations. cblC presenting with pulmonary hypertension (PH) as leading sympotom is rare and easily misdiagnosed because of limited awareness. Timely diagnosis is crucial by the relentless progression without appropriate treatment.
\end{abstract}

Case presentation: We reported a 12-year-old girl with a 3-year history of progressively reduced activity tolerance and a 3-month history of orthopnea. Metabolic testing revealed increased levels of plasma homocysteine and urine methylmalonic acid. cblC deficiency was subsequently confirmed by genetic testing. The patient was treated with hydroxocobalamin, betaine, folinic acid and levocarnitine for cblC disease. Sildenafil, bosentan, spironolactone and hydrochlorothiazide was administrated for $\mathrm{PH}$ and right heart failure. At 3-month follow-up, she had an apparent resolution of dyspnea and cyanosis. Metabolic abnormalities resolved the decrease of plasma homocysteine and urine methylmalonic acid. A right heart catheterization showed a reduced pulmonary pressure.

Conclusions: This case emphasizes the importance of an early diagnosis and initiation of treatment for cblC deficiency. Unexplained PH in children and young adults should prompt metabolic screening for the differential diagnosis.

Keywords: Cobalamin C deficiency, Pulmonary hypertension, Methylmalonic aciduria, Homocystinemia

\section{Background}

Methylmalonic aciduria and homocystinemia, cobalamin $\mathrm{C}(\mathrm{cblC})$ type is a rare genetic metabolic disease, with an estimated prevalence of one per 11,160 to 250,000 population worldwide [1]. The clinical manifestations and age of presentation of cblC are heterogeneous. Late-onset cblC deficiency refers patients that have symptoms after 4 years of age [2]. They usually present with a milder

* Correspondence: shixiaoqing0116@163.com

${ }^{2}$ Department of Cardiology, Key Laboratory of Birth Defects and Related Diseases of Women and Children of Ministry of Education, West China Second University Hospital, Sichuan University, 20\# Section 3 South Renmin Road, Chengdu, Sichuan, China

Full list of author information is available at the end of the article phenotype typically including neurologic and developmental abnormalities. Pulmonary hypertension $(\mathrm{PH})$ in patients with cblC deficiency is rare but lethal complications. To our knowledge, only 4 late-onset cblC deficiency patients have been reported to have $\mathrm{PH},[3-6]$ and none of them were first-presentation in $\mathrm{PH}$ patients. Here, we report a 12-year-old girl with cblC deficiency, who presented with $\mathrm{PH}$ as her first symptom.

\section{Case presentation}

A 12-year-old girl with a 3-year history of progressively reduced activity tolerance and a 3-month history of orthopnea presented to the emergency department. On physical examination, her blood pressure was 106/59 $\mathrm{mmHg}$, heart rate was regular at 120 beats per minute,

C The Author(s). 2020 Open Access This article is licensed under a Creative Commons Attribution 4.0 International License, which permits use, sharing, adaptation, distribution and reproduction in any medium or format, as long as you give appropriate credit to the original author(s) and the source, provide a link to the Creative Commons licence, and indicate if changes were made. The images or other third party material in this article are included in the article's Creative Commons licence, unless indicated otherwise in a credit line to the material. If material is not included in the article's Creative Commons licence and your intended use is not permitted by statutory regulation or exceeds the permitted use, you will need to obtain permission directly from the copyright holder. To view a copy of this licence, visit http://creativecommons.org/licenses/by/4.0/ The Creative Commons Public Domain Dedication waiver (http://creativecommons.org/publicdomain/zero/1.0/) applies to the data made available in this article, unless otherwise stated in a credit line to the data. 
respiratory rate was 35 breaths per minute, and oxygen saturation level was $88 \%$ under nasal oxygen inhalation. The patient was afebrile. She had no sign of headache, convulsions, epilepsy and changes in urine volume. Also, neruologic, psychiatric and ophthalmologic evaluation showed no positive signs. Physical examination revealed accentuated P2 cardiac sounds, a grade II systolic and diastolic murmur along the left sternal border, mild bibasilar crackles, and lower extremity edema. She had no significant medical, surgical or family history and no history of alcohol or drug use. She was born at term by natural birth. Birth parameters were normal. Her baseline weight was $40 \mathrm{~kg}$ (BMI, $\left.15.4 \mathrm{~kg} / \mathrm{m}^{2}\right)$.

A 12-lead electrocardiogram showed $\mathrm{T}$ wave changes in lead II, III, aVF, V3-6 and ST segment depression. Laboratory test results are summarized in Table 1. Abnormal laboratory findings included elevated $\mathrm{N}$-terminal-pro B-type natriuretic peptide, elevated plasma uric acid, elevated creatinine and decreased red cell count. Blood electrolytes and liver function were within reference limits. Urine dipstick showed no microscopic haematuria and proteinuria. A transthoracic echocardiogram revealed dilated right ventricle (the inter-ventricular measurement of right ventricle is $48 \mathrm{~mm}$ ), widened pulmonary artery trunk (immediately above the valve, $33 \mathrm{~mm}$ ), tricuspid regurgitation (mild), and pulmonary regurgitation (mild-moderate) (Fig. 1). Cardiac magnetic resonance imaging confirmed impaired biventricular function (right ventricular ejection fraction: $15.6 \%$ and left ventricular ejection fraction: $38.9 \%$ ) with late enhancement at the inferior right ventricular insertion point (Fig. 2). Cardiac catheterization showed a mean pulmonary artery pressure of $55 \mathrm{mmHg}$, pulmonary artery wedge pressure of $30 \mathrm{mmHg}$, pulmonary vascular resistance of 8.7 woods units and the withered tree

Table 1 Laboratory test results of first admission

\begin{tabular}{lll}
\hline Test name & Result & Normal range \\
\hline $\begin{array}{l}\text { N-terminal-pro B-type natriuretic } \\
\text { peptide }(\mathrm{pg} / \mathrm{mL})\end{array}$ & 3879.2 & $0-100$ \\
Troponin (ug/L) & 0.045 & $0-0.06$ \\
Plasma uric acid (umol/L) & 510 & $184-464$ \\
Plasma creatinine (umol/L) & 82 & $24.8-70.4$ \\
Plasma urea (mmol/L) & 8.25 & $3.2-8.2$ \\
Serum platelet count $\left(10^{9} / \mathrm{L}\right)$ & 220 & $100-450$ \\
Red cell count $\left(10^{12} / \mathrm{L}\right)$ & 2.5 & $3.82-5.5$ \\
Hemogloblin $(\mathrm{g} / \mathrm{L})$ & 110 & $110-146$ \\
Serum iron $(\mathrm{umol} / \mathrm{L})$ & 3.9 & $9.0-30.4$ \\
Serum $\mathrm{B}_{12}(\mathrm{pmol} / \mathrm{L})$ & 389.51 & $182-672$ \\
Serum folic acid $(\mathrm{nmol} / \mathrm{L})$ & 31.41 & $>12.19$ \\
\hline
\end{tabular}

sign. An additional movie file shows this in more detail [see Additional file 1].

The main features of the patient were unexplained $\mathrm{PH}$, right-sided heart failure, and impaired renal function. Renal metabolic function tests showed elevated plasma homocysteine $(155.8 \mu \mathrm{mol} / \mathrm{L}, 5-15)$, which suggested the possibility of systemic genetic disease, i.e., methylmalonic aciduria and homocystinemia, the genetic disease of vitamin $\mathrm{B}_{12}$ metabolism. Further metabolic testing revealed elevated urine methylmalonic acid $(49.7 \mathrm{mmol} /$ $\mathrm{molCr})$, elevated plasma propionylcarnitine $(7.3 \mu \mathrm{mol} / \mathrm{L}$, $0.2-5)$, and decreased plasma methionine $(6.2 \mu \mathrm{mol} / \mathrm{L}$, 8-45). A cobalamin C (cblC) deficiency was subsequently confirmed by genetic testing of the MMACHC gene, revealing a compound heterozygous c.80A $>$ G/ c.609G > A genotype.

The patient was treated with hydroxocobalamin $(1 \mathrm{mg}$, intramuscular, q.d.), betaine (1000 mg, peros, q.d.), folinic acid (5 mg, peros, t.i.d.), and levocarnitine $(10 \mathrm{ml}$, peros, b.i.d.) for cblC disease. Sildenafil $(20 \mathrm{mg}$, peros, t.i.d.), bosentan (62.5 mg, peros, b.i.d.), spironolactone (20 mg, peros, b.i.d.), and hydrochlorothiazide $(25 \mathrm{mg}$, peros, b.i.d.) were administrated for $\mathrm{PH}$ and right-sided heart failure. At the 3-month follow-up, she had an apparent resolution of dyspnea and cyanosis. The metabolic abnormalities appeared to be resolving, as observed by a decrease in urine methylmalonic acid $(6.32 \mathrm{mmol} /$ $\mathrm{molCr})$ and plasma homocysteine $(119.8 \mu \mathrm{mol} / \mathrm{L} ; 5-15))$, along with a reduction in plasma uric acid $(428 \mu \mathrm{mol} / \mathrm{L})$ and creatinine $(53 \mu \mathrm{mol} / \mathrm{L})$. A second right heart catheterization showed reduced pulmonary artery pressure $(52 / 30,38 \mathrm{mmHg})$. Cardiac magnetic resonance imaging revealed a decrease in the size of the right ventricle and pulmonary trunk and an increase in biventricular function (right ventricular ejection fraction: $29.3 \%$, left ventricular ejection fraction: $56.2 \%$ ).

\section{Discussion and conclusion}

Methylmalonic aciduria and homocystinemia, cblC type, is a rare genetic disease of vitamin $\mathrm{B}_{12}$ metabolism. It is caused by a mutation in the $M M A C H C$ gene and results in abnormal concentrations of downstream metabolites of the cobalamin pathway [2]. The classical biochemical pattern of this disease is the accumulation of methylmalonic acid and homocysteine, with decreased methionine production. The diagnosis of cblC disease can be challenging due to highly variable clinical manifestations and ages of presentation. The early-onset form is usually multisystemic and progressive, with severe neurologic, ocular, hematologic, renal, gastrointestinal, and cardiac symptoms during the first year after birth. The lateonset form presents after 4 years of age with a mild and limited phenotype ranging from a predominantly neurologic disorder to multisystemic disturbances [2]. Isolated 


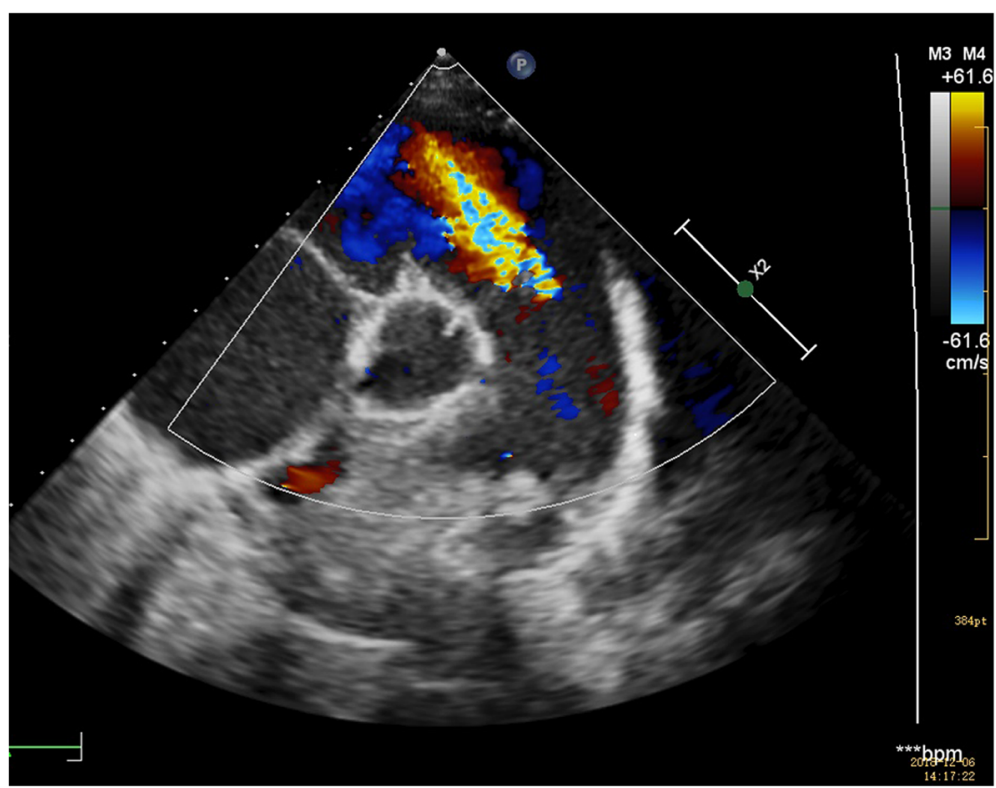

Fig. 1 Transthoracic echocardiogram demonstrates widened pulmonary artery trunk and pulmonary regurgitation

$\mathrm{PH}$ or combined renal dysfunction is one of the rare phenotypes of the late-onset form [3-6]. The mechanism whereby $M M A C H C$ mutation might cause $\mathrm{PH}$ is unelucidated. It may be that the combined results of vasculopathy and thrombosis are triggered by endothelial dysfunction. The diagnosis of cblC disease is mainly based on biochemical parameters [2] and genetic testing. c. $80 \mathrm{~A}>\mathrm{G}$ and c.609G > A were two common mutations in Chinese cblC type patinets and were reported to be associated with late-onset cblC disease. The three most common mutations in the MMACHC gene are c.271dupA, c.394C $>\mathrm{T}$ and c.331C $>\mathrm{T}$ [7]. Plasma homocysteine, urine organic acids and plasma acylcarnitine should be assessed when a cobalamin-related disorder is suspected [8]. $\mathrm{VB}_{12}$ insufficiency needs to be taken into consideration for differential diagnosis.
Pediatric $\mathrm{PH}$ is an important cause of morbidity and mortality in children. Data from the Tracking Outcomes and Practice in Pediatric Pulmonary Hypertension study has revealed that idiopathic or genetic $\mathrm{PH}$ accounted for $57 \%$ of registered pediatric $\mathrm{PH}$ patients, of which $43 \%$ of cases were associated with systemic disorders [9]. The reported age at diagnosis for idiopathic or genetic $\mathrm{PH}$ is usually younger (range: 0.9-11.1 years) than this patient [10]. Previous reports [3-6] on cblC disease with $\mathrm{PH}$ always exhibit renal thrombotic microangiopathy at the same time, which cause clinicians' attention to systemic metabolic desease. This case enlarges the clinical spectrum of late-onset cblC deficiency. Further work is needed to understand the prevalence of $\mathrm{CblC}$ in children and young adults with idiopathic/unexplained $\mathrm{PH}$.
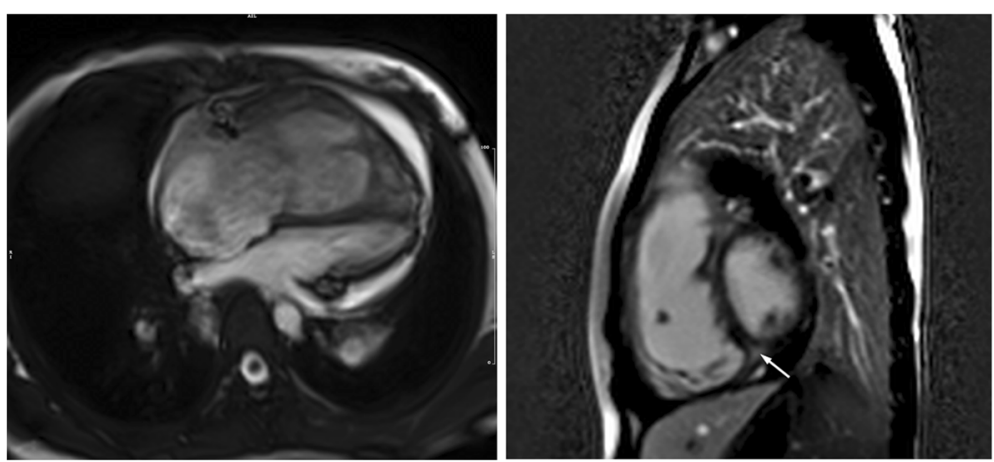

Fig. 2 Cardiac magnetic resonance imaging confirms dilated right ventricle with late enhancement at the inferior right ventricular insertion point (arrow) 
Therapeutic goals are to improve clinical symptoms, normalized methionine, methylmalonic acid and homocysteine once diagnosed. Hydroxocobalamin and betaine treatment should be initiated as soon as there is a suspicion of cblC disease, and targeted $\mathrm{PH}$ therapy has improved survival in idiopathic and genetic $\mathrm{PH}[2,11]$. Conventional therapies for heart failure are also utilized for the treatment of children with right ventricular failure.

In conclusion, cblC deficiency presenting with $\mathrm{PH}$ as leading sympotom is rare and easily misdiagnosed. The diagnosis of cblC deficiency is mainly based on biochemical parameters and genetic testing. For children and young adults with unexplained $\mathrm{PH}$ should prompt metabolic screening, plasma homocysteine, urine organic acids and plasma acylcarnitines testing and early treatment for cblC deficiency if diagnosed. Early recognition and timely treatment may beneficially affect the course of cblC deficiency.

\section{Supplementary information}

Supplementary information accompanies this paper at https://doi.org/10. 1186/s12887-020-02130-9.

Additional file 1. Video illustrates the withered tree sign. (AVI 3465 kb)

Abbreviations

cblC: Cobalamin C; PH: Pulmonary hypertension

\section{Acknowledgements}

Not applicable.

\section{Authors' contributions}

XQS was in charge of case evaluation and interpretation. LYW collected raw materials and wrote the case report. YKG interpreted the imaging data and revised the report. All authors have approved the manuscript for submission and takes responsibility for the integrity of the data.

\section{Funding}

No funding.

Availability of data and materials

The datasets used during the current study are included in the manuscript.

Ethics approval and consent to participate

Not applicable.

\section{Consent for publication}

Consent form was signed and obtained from the patient and patient's parent for the publication of the case report

\section{Competing interests}

The authors declare that they have no competing interests.

\section{Author details}

${ }^{1}$ Department of Radiology, Key Laboratory of Birth Defects and Related Diseases of Women and Children of Ministry of Education, West China Second University Hospital, Sichuan University, Chengdu, Sichuan, China. ${ }^{2}$ Department of Cardiology, Key Laboratory of Birth Defects and Related Diseases of Women and Children of Ministry of Education, West China Second University Hospital, Sichuan University, 20\# Section 3 South Renmin Road, Chengdu, Sichuan, China.
Received: 7 March 2020 Accepted: 6 May 2020

Published online: 22 May 2020

References

1. Zhou X, Cui Y, Han J. Methylmalonic acidemia: current status and research priorities. Intractable Rare Dis Res. 2018:7(2):73-8.

2. Carrillo-Carrasco N, Chandler RJ, Venditti CP. Combined methylmalonic acidemia and homocystinuria, cblC type. I. Clinical presentations, diagnosis and management. J Inherit Metab Dis. 2012;35(1):91-102.

3. Komhoff M, Roofthooft MT, Westra D, et al. Combined pulmonary hypertension and renal thrombotic Microangiopathy in Cobalamin C deficiency. Pediatrics. 2013;132(2):e540-4.

4. Losito A, Pittavini L, Covarelli C. Thrombotic microangiopathic nephropathy, pulmonary hypertension and nephromegaly: case report of a patient treated with endothelin receptor antagonist. Clin Nephrol. 2012;77(2):164-70.

5. Petropoulos TE, Ramirez ME, Granton J, et al. Renal thrombotic microangiopathy and pulmonary arterial hypertension in a patient with late-onset cobalamin C deficiency. Clin Kidney J. 2018;11(3):310-4.

6. Steven G, Soumeya B, Elise AM, et al. Adult-onset renal thrombotic microangiopathy and pulmonary arterial hypertension in cobalamin C deficiency. Lancet. 2015;386(9997):1011-2.

7. Lerner-Ellis JP, Tirone JC, Pawelek PD, et al. Identification of the gene responsible for methylmalonic aciduria and homocystinuria, cblC type. Nat Genet. 2006;38:93-100.

8. Huemer M, Diodato D, Schwahn B, et al. Guidelines for diagnosis and management of the cobalamin-related remethylation disorders $\mathrm{CblC}$, cblD, cblE, cblF, cblG, cblJ and MTHFR deficiency. J Inherit Metab Dis. 2017:40(1):21-48

9. Berger RM, Beghetti M, Humpl T, et al. Clinical features of paediatric pulmonary hypertension: a registry study. Lancet. 2012;379(9815):537-46.

10. van Loon $\mathrm{RL}$, Roofthooft MT, Hillege $\mathrm{HL}$, et al. Pediatric pulmonary hypertension in the Netherlands: epidemiology and characterization during the period 1991 to 2005. Circulation. 2011;124(16):1755-64.

11. Ivy DD, Abman SH, Barst RJ, et al. Pediatric pulmonary hypertension. J Am Coll Cardiol. 2013;62(25):D117-26.

\section{Publisher's Note}

Springer Nature remains neutral with regard to jurisdictional claims in published maps and institutional affiliations.
Ready to submit your research? Choose BMC and benefit from:
- fast, convenient online submission
- thorough peer review by experienced researchers in your field
- rapid publication on acceptance
- support for research data, including large and complex data types
- gold Open Access which fosters wider collaboration and increased citations
- maximum visibility for your research: over $100 \mathrm{M}$ website views per year
At BMC, research is always in progress.
Learn more biomedcentral.com/submission 